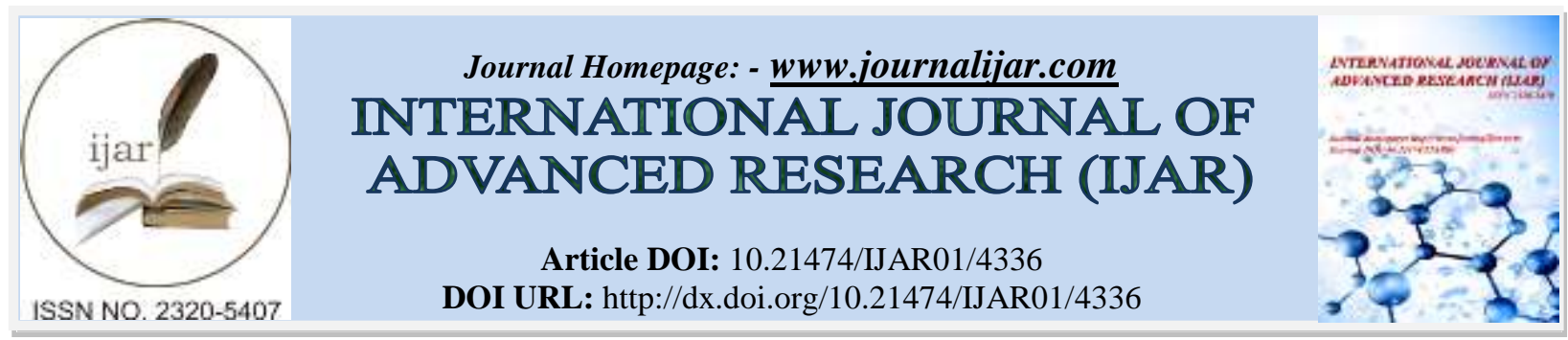

RESEARCH ARTICLE

\title{
INTERACTION BETWEEN CHLOROQUINE SULPHATE AND COCONUT FRUIT WATER IN ADULT MALE RABBITS.
}

\section{Patience C. Nwonu" ${ }^{1}$, Reginald O. Obidike ${ }^{2}$ and "Chukwunwike N. S. Nwonu" ${ }^{3}$.}

1. Department of Pharmacology and Toxicology, Faculty of Pharmaceutical Sciences, University of Nigeria, Nsukka, Enugu State, Nigeria.

2. Department of Pharmacology and Therapeutics, Faculty of Basic and Allied Medical Sciences, College of Health Sciences, Benue State University, P.M.B. 102119, Makurdi, Nigeria.

3. Lecturer, Department of Pharmacology and Therapeutics, Faculty of Basic and Allied Medical Sciences, College of Health Sciences, Benue State University, P.M.B. 102119, Makurdi, Nigeria.

\section{Manuscript Info}

(.........................

Manuscript History

Received: 14 March 2017

Final Accepted: 17 April 2017

Published: May 2017

\section{Key words:-}

Coconut fruit water, chloroquine sulphate, pharmacokinetic parameters, co-administration, pharmacokinetic interaction and rabbits.

\section{Abstract}

Inconsistent scientific reports have trailed the use of coconut fruit water in inhibiting the effect of poisons, including its use in the immediate therapeutic management of drug over-dosagein both humans and animal studies. The study investigated the possible interaction of the concomitant administration of chloroquine sulphate and coconut fruit water in adult male rabbits. Two groups of rabbits (five each) were used in the experiment, and both served as test and control groups respectively. The control group received chloroquine sulphate only while in the test group, chloroquine sulphate and coconut fruit water were co-administered to mature adult male rabbits. The pharmacokinetic profile of both the control and the test groups were determined spectrophotometrically using centrifuged blood samples of the animals at different time intervals. The result of the experiment demonstrated a significant decrease in the mean plasma concentration, peak serum concentration and the volume of distribution in the test group. There was no significant difference in the time to peak plasma concentration in the test and control groups, but there was a significant decrease in the biological half-life of chloroquine sulphate in the test group. The mean serum concentration of chloroquine sulphate in the test group was decreased by $53.89 \mathrm{mg} \%$ relative to the control group, while the maximum serum concentration of chloroquine sulphate in the test group was decreased by $31.67 \mathrm{mg} \%$. The result also, demonstrated an increase in the clearance rate, absorption rate constant and the elimination rate constant in the test group. The study, therefore, concluded that there is a strong in vivo pharmacokinetic interaction between chloroquine sulphate and coconut fruit water, and this affects bioavailability, thus decreasing the mean plasma concentration of chloroquine sulphate. 


\section{Introduction:-}

Coconut is the common name for the fruit of a tree, Cocos nucifera Linn. family (Arecaceae/Palmae), which is widely distributed in the tropics (Sivakumar et al., 2011). It is an edible plant and not very common ethnomedically. The coconut palm has a single cylindrical trunk about $45 \mathrm{~cm}$ in diameter and can grow to 20-30 m high, with many rings marking the places of former leaves (Muanya, 2009). Coconut palm is a monocotyledon perennial plant cultivated in the tropics for its fruit and fibre (Hahn, 1997; Coconut Research Centre, 2004 and Kew, 2011). At the apex of the plant, it bears a crown of about 20 pinnate leaves that generally curve downwards of which each leaf is between 3.0-4.5 m long (Ali and Qaiser, 2008; Missouri, 2008). The fruit grows in bunches of 10-20 or more nuts, and 10 or 12 of these bunches may be seen in a single coconut plant at various stages of development. The mature coconut is elliptical in shape, about $15-25 \mathrm{~cm}$ in length, green or yellowish in colour, and possesses a thick, fibrous outer husk covering a hard inner shell (Ali and Qaiser, 2008; Missouri, 2008). The woody, inner wall is lined by a white endosperm matter and a sweet-tasting, milky fluid containing cytokinins (Ali and Qaiser, 2008; Missouri, 2008). When given the right care and growing environmental conditions, coconut palms produce their first fruits in 6-10 years, and it takes 15-20 years to attain maximum production (Coconuts, 2010). Coconut fruit water contains sugar, vitamins, minerals, proteins, free amino acids and growth producing factors (Muanya, 2009). Some medicinal properties have been found in coconut fruit water, and they include; saline and albumin contents make it a good drink for cholera patients; combating urinary infection and diarrhoea; treatment of kidney and urethral stones; hastens the absorption of drugs; possesses antiseptic activity and thus eliminates poisons, especially mineral poisons (Cocoinfo International, 2004). Coconut fruit water is generally believed to be an antidote to the undesirable and toxic effects of drugs. It is reported to have antidiabetic potential (Muanya, 2009). A recent study has also, shown that coconut fruit water does not have any protective effects on the liver against toxicity of acetaminophen overdosage (Effiong et al., 2010).

Chloroquine is a member of a large series of 4-aminoquinolines, and was previously, the mainstay in the prevention and treatment of acute malaria attacks, until the emergence of resistant strains of Plasmodium falsiparum in the 1980s. It is commercially available as sulphate or phosphate (WHO, 1995). The fundamental molecular mechanism of action of chloroquine is obscure. Chloroquine is a weak base, and exert blood schizonticidal action against the asexual form of the parasite (Kamalakannan, 2013; Chloroquine, 2015). It concentrates to a very high level in the acidic food vacuoles of the parasite and increases the $\mathrm{pH}$ of sensitive malarial parasites, where they interfere with lysosomal degradation of host haemoglobin (a source of amino acid for the parasite) and cause histological abnormalities characteristic of the 4-aminoquinolines, e.g., the inhibition of heme polymerase enzyme resulting in the accumulation of heme, which causes the lysis of the parasite membrane and their death ultimately (Udaykumar, 2013). Aside chloroquine being used as an antimalarial, it can be used in rheumatoid arthritis due to their antiinflammatory property (Udaykumar, 2013; Chloroquine, 2015). It is also, used in extraintestinal amebiasis as well as discoid lupus erythematosus (Udaykumar, 2013; Chloroquine, 2015).

\section{Materials and Methods:-}

\section{Phytochemical screening of coconut fruit water:-}

The chemical composition of coconut fruit water are phytohormones (auxins, gibberellins, ethylene, cytokinins and abscisic acid (Kende and Zeebvaart, 1997; $\mathrm{Ma}$ et al., 2008; $\mathrm{Wu}$ and $\mathrm{Hu}, 2009$ ). Inorganic ions include $\mathrm{Na}^{+}, \mathrm{K}^{+}, \mathrm{Mg}^{2+}$ and $\mathrm{Ca}^{2+}$ (Saat et al., 2002). Others are vitamins $\mathrm{B}_{1}, \mathrm{~B}_{2}, \mathrm{~B}_{3}, \mathrm{~B}_{6}, \mathrm{~B}_{7}, \mathrm{~B}_{9}$ and $\mathrm{C}$ (Shenkin, 2006). Coconut fruit water also, contains fats, sugars (glucose, fructose and sucrose), sugar alcohols (mannitol, sorbitol, myo-inositol and scyllo-inositol). Amino acids present in coconut fruit water include glutamic acid, glutamine, glycine, methionine, tyrosine etc. There are also, nitrogenous compounds (such as ammonia and ethanolamine) and organic acids, e.g., citric acid, tartaric acid and malic acid (Santoso et al., 1996 and USDA, 2008)

\section{Collection of plant materials:-}

Five fresh nuts of Cocos nucifera were purchased in the month of August, 2016 from Ogige market, Nsukka, Enugu State, Southeastern Nigeria, and these nuts were subsequently used for the experiment.

\section{Equipment:-}

The equipment employed in this study are: syringes of varying capacities, measuring cylinder, 23 -guage needles, test tubes, mettler weighing balance, UV spectrophotometer (Sp 8-100, Pyesecam, England), evaporating and weighing dishes, centrifuge (Model No. Whisperfuge, Diamon/IEC Division, England), Cotton wool, masking tape, spatula, cannula, conical flask, bijou bottle and filter papers. 


\title{
Chemical reagents:-
}

These are: ammonia solution, diethyl ether (Riedel-De Haen, AG Seelze-Hanover), hydrochloric acid, distilled water, xylene, physiologic saline, ethanol, chloroquine sulphate capsules (Nivaquine Forte-Roche, May and Baker Ltd., Nigeria), potassium edentate.

\begin{abstract}
Animals:-
Five mature healthy adult male rabbits weighing between 1.10-1.80 kg were obtained from a local breeder at Nkwo Ibagwa market, Igbo-Eze South Local Government Area, Enugu State, Southeastern Nigeria. The animals were housed under good environmental conditions of 12/12 h light/dark cycle in cross ventilated rooms, with the home cages regularly cleaned, at the animal facility of the Department of Pharmacology and Toxicology, Faculty of Pharmaceutical Sciences, University of Nigeria, Nsukka. They were fed with carpet grasses (Panicum maximum) for 14-days to ensure good acclimatization. The rabbits had water ad libitum. The guidelines for the use and care of animals for research was strictly adhered to (NIH, 1991; NRC, 1996).
\end{abstract}

\section{Experimental Model:-}

The serum method is one of the techniques employed in evaluating the in vivo effect of coconut fruit water in chloroquine absorption, and will be used in this study. In this technique, the amount of chloroquine absorbed can be obtained directly from the blood. The blood sample is collected after chloroquine absorption, and the chloroquine subsequently extracted and its concentration determined from the calibration curve (Ehiemua et al., 1987).

\section{Preparation of drug sample:-}

Five capsules of chloroquine sulphate $(250 \mathrm{mg}$ each) were emptied and weighed in an electronic balance. They were crushed to powder in a mortar using a pestle, and put in a clean dry bijou bottle, and stored in a cool dry place. A specific amount of the drug was weighed and a particular stock concentration was prepared using distilled water.

\section{Preparation of coconut fruit water extract:-}

The coconut fruit water was obtained by breaking the coconut shell and pouring the entire coconut fruit water into a clean dry beaker using a filter paper, and used for experiment, while the remnant was refrigerated for future use.

\section{Determination of wavelength of maximum absorption:-}

The wavelength of maximum absorption ( $\wedge$ Max) for chloroquine sulphate is determined by weighing and preparing a given concentration of chloroquine sulphate using distilled water. The stock concentration prepared is then placed in a curvette of ultraviolet spectrophotometer and scanned, while recording the value of lamda max.

\section{Determination of serum drug concentration:-}

The animals had an overnight fast $(12 \mathrm{~h})$ before the experiment. The study was carried out in two phases, A and B. Phase A: Chloroquine sulphate $(15 \mathrm{mg} / \mathrm{kg}$, p.o.) was administered to each of the five healthy mature adult male rabbits, after blood samples were collected from the marginal ear vein of the rabbits, and thus served as the blank sample. After chloroquine administration, blood samples were collected at 1, 2, 4, 8 and $24 \mathrm{~h}$ intervals. The collected blood samples were centrifuged, stored in test tubes in a refrigerator until they were needed for analysis. Phase B: The animals were allowed for 7-days to allow for complete clearance of the drug from the system before this phase is begun. Each rabbit is administered chloroquine sulphate $(15 \mathrm{mg} / \mathrm{kg}$, p.o.) and coconut fruit water (8 $\mathrm{ml} / \mathrm{kg}$, p.o.) concurrently. After the administration of these agents, blood samples were collected at different time intervals viz. 1, 2, 4, 8 and $24 \mathrm{~h}$. The blood samples collected were centrifuged and stored in a refrigerator until they are needed for analysis.

\section{Blood sample analysis:-}

The analysis involves the extraction of the chloroquine sulphate from the blood sample and the subsequent analysis to determine its concentration. The absorption of the chloroquine sulphate solution was determined at a wavelength of $328 \mathrm{nM}$ while the concentration of chloroquine was deduced from the calibration curve. The blood samples result was further analyzed using various pharmacokinetic parameters.

\section{Statistical analysis:-}

All data were expressed as mean \pm standard error of the mean (mean \pm S.E.M.). Analysis of data was performed using the student T-test. The level of statistical significance was accepted at $5 \%(\mathrm{P}<0.05)$. 


\section{Results:-}

The concentration of chloroquine sulphate alone, and that of chloroquine sulphate and coconut fruit water in the serum at different time intervals were obtained.

Table 1:- Mean plasma concentrations of chloroquine sulphate alone versus time; andchloroquine sulphate plus coconut fruit water versus time.

\begin{tabular}{|c|l|l|}
\hline $\begin{array}{c}\text { Time } \\
(\mathrm{h})\end{array}$ & Mean plasma concentration $(\mathrm{mg} \%)$ & Mean plasma concentration $(\mathrm{mg} \%)$ \\
\hline & Chloroquine sulphate alone & Chloroquine sulphate + Coconut fruit water \\
\hline 0.0 & $0.000 \pm 0.000$ & $0.000 \pm 0.000$ \\
\hline 1.0 & $2.725 \pm 0.102$ & $1.862 \pm 0.038$ \\
\hline 2.0 & $1.697 \pm 0.025$ & $0.991 \pm 0.020$ \\
\hline 4.0 & $1.172 \pm 0.036$ & $0.542 \pm 0.023$ \\
\hline 8.0 & $1.152 \pm 0.018$ & $0.524 \pm 0.077$ \\
\hline 24.0 & $0.949 \pm 0.043$ & $0.331 \pm 0.027$ \\
\hline
\end{tabular}

Table 2:- Summary of the pharmacokinetic parameters

\begin{tabular}{|l|l|l|l|l|l|l|l|l|}
\hline Group & $\begin{array}{l}\text { AUC } \\
(\mathrm{mg} \%)\end{array}$ & $\begin{array}{l}\text { Cmax } \\
(\mathrm{mg} \%)\end{array}$ & $\begin{array}{l}\text { Tmax } \\
(\mathrm{h})\end{array}$ & $\mathrm{T}_{1 / 2}$ & $\begin{array}{c}\text { Clearance } \\
(\mathrm{h})\end{array}$ & $\mathrm{Ka}$ & $\mathrm{Ke}$ & $\mathrm{Vd}$ \\
\hline $\begin{array}{c}\mathrm{CQSO}_{4} \\
\text { Alone }\end{array}$ & 27.899 & 2.725 & 1.000 & 21.920 & 0.489 & 3.090 & 0.032 & 15.466 \\
\hline $\begin{array}{c}\mathrm{CQSO}_{4} \\
+ \\
\text { Coconut }\end{array}$ & 12.863 & 1.862 & 1.000 & 12.430 & 0.671 & 3.190 & 0.056 & 12.031 \\
\hline
\end{tabular}

\section{Discussion:-}

Coconut fruit water is a natural, sterilized and mineral isotonic beverage, and a healthy electrolyte drink (Anuradha, 2010). Coconut fruit water helps to detoxify the body. It is the strongest antidote, especially against poison infusion (Anuradha, 2010). It has saved life of many poisoned victims, and possesses the ability to neutralize the effects of poison (Anuradha, 2010). Coconut fruit water is generally believed to be an antidote to the undesirable and toxic effects of drugs.

The result of the experiment demonstrated a significant decrease in the mean plasma concentration of chloroquine sulphate, as well as when chloroquine was co-administered withcoconut fruit water. There was also, a decrease in the peak serum concentration and the volume of distribution in the test group (i.e. chloroquine sulphate and coconut fruit water). There was no significant difference in the time to peak plasma concentration in the test and control group (i.e. chloroquine sulphate alone), but there was a significant decrease in the biological half-life of chloroquine sulphate in the test group. The mean serum concentration of chloroquine sulphate in the test group was decreased by $53.89 \mathrm{mg} \%$ relative to the control group, while the maximum serum concentration of chloroquine sulphate in the test group was decreased by $31.67 \mathrm{mg} \%$. The result also, demonstrated an increase in the clearance rate, absorption rate constant and the elimination rate constant in the test group.

The observed differences in the pharmacokinetic parameters of chloroquine sulphate alone, and when chloroquine sulphate was co-administered with coconut fruit water, are partly due to the degree of the drug absorption into the systemic circulation from the gut. This may be as a result of the physical interaction between chloroquine sulphate and coconut fruitwater. Coconut fruit water contains amino acids (e.g. zwitterion, a dipolar form of amino acid and a neutral molecule with both positive and negative electrical charges) which could form complexes with administered chloroquine sulphate, and thus decrease the absorption of chloroquine. The degree of dissociation and ionization of drugs, and the $\mathrm{pH}$ of the internal environment (milleu interior) of an organism play a critical role in the transfer of drugs across biological membranes. The $\mathrm{pH}$ of coconut fruit water is slightly alkaline, and this may lead to the ionization of chloroquine sulphate, and thus impairs its absorption. Coconut fruit water probably mediates its action by inhibiting the absorption of drugs through the formation of zwitterion-drug complex, a large particle size and high molecular weight substance that is impermeable to biological membranes. 


\section{Conclusion:-}

The study concluded that the co-administration of chloroquine sulphate and coconut fruit waterin vivo markedly impairs the bioavailability of chloroquine.

\section{References:-}

1. Sivakumar MK, Moideen MM, Varghese R, Dhanapal B (2011). Preliminary phytochemical screening and antibacterial activity of Cocos nucifera Linn. Root. Res. J. Pharmaceut. Biol. Chem. Sci. 2(4): 468.

2. Muanya C (2009). Researchers validate coconut fruit water as natures energy drink.

3. CI (2004). Cocoinfo International 2(1): ISBN $0854-5006$.

4. Effiong GS, Ebong PE, Eyong AJ, Uwah AJ, Ekong UE (2010). Amelioration of chloroquine-induced toxicity by coconut water in rats. J. Applied Sci. Res. 6(4): $331-335$.

5. Kende H, Zeevaart J (1997). The five classical plant hormones. Plant cell 9: 1197 - 1210.

6. Ma Z, Ge L, Lee ASY, Young JWH, Tan SN, Ong ES (2008). Simultaneous analysis of different classes of phytohormones in coconut (Cocos nucifera L.) water using high-performance liquid chromatography and liquid chromatography tandem mass spectrophotometry after solid-phase extraction. Anal. Chim. Acta. 600: 274 281.

7. NIH (1991) Guidelines for the care and use of animals in neuroscience and behavioueal research. National Institutes of Health.

8. NRC (1996): Guidelines for the care and use of animals in neuroscience and behavioural research. National Research Council. Academic Press: Washington, DC. 12.

9. Wu Y, Hu B (2009). Simultaneous determination of several phytohormones in natural coconut juice by hollow fibre-based liquid-liquid-liquid microextraction-high performance liquid chromatography. J. Chromatogr. A. 1216: $7657-7663$.

10. Shenkin A (2006). The key role of micronutrients. Clinical nutrition 25: $1-13$.

11. Depeint F, Bruce WR, Shangari N, Mehta R, O' Brien PJ (2006). Mitochondrial function and toxicity: Role of B-vitamins on the one carbon transfer pathways. Chem. Biol. Interact. 163: $113-132$.

12. Santoso U, Kubo K, Ota T, Tadokoro T, Maekawa A (1996). Nutrient composition of kopyo coconuts (coconut milk) (Cocos nucifera L.). Food Chem. 57: 299 - 304.

13. USDA (2008). United States Department of Agriculture. National Nutrient Database for Standard Reference.

14. Ali SI, Quiser M (2008). Flora of Pakistan Vol. 0: 12.

15. Missouri (2008). Missouri Botanical Garden 4344 Shaw Boulevard, St. Louis, MO, 63110, USA.

16. CRC (2004). Coconut Research Centre, Colorado Springs CO 80936, USA.

17. Hahn WJ (1997). Arecanae: The palms. Tree of life project website.

18. Coconuts (2010). www.homeguides.sfgate.com/long-coconuttree-coconut-84353.html

19. Kew (2011). Royal Botanical Garden, Kew, England.

20. Chloroquine (2015). The American Society of Health System Pharmacists December 2, Wikipedia.

21. WHO (1995). Essential medications and health products information portal.

22. Ehiemua AO, Komolafe OO, Oyedeji GA, Olamijulo SK (1987). Effect of promethazine on the metabolism of chloroquine. Materia Med. Pol. 14664: 225 - 226.

23. Udaykumar P (2013). Medical pharmacology, $4^{\text {th }}$ ed., CBS Publishers and Distributors PVT Ltd., New Delhi, India: $477-478$.

24. Kamalakannan (2013). Textbook of pharmacology for nurses and allied health sciences, $1^{\text {st }}$ ed., CBS Publishers and Distributors PVT Ltd., New Delhi, India: 308 - 311. 